caution because of the uncertainty in the measured value of the momentum of the incident particle.

One further general comment may be made. This is that the observation of two spontaneous disintegrations in such a small number of penetrating showers suggests that the life-time of the unstable particles is much less than the life-time of the ordinary meson. An approximate value of this life-time may be derived as follows. The probability of an unstable particle of life-time $\tau_{0}$ decaying in a short distance $D$ is given by

$$
p=\frac{D\left(1-\beta^{2}\right)^{1 / 2}}{\tau_{0} c \beta} .
$$

Since the total number of penetrating particles in the penetrating showers so far observed is certainly less than 50, we must assume that the number of our new unstable particles is unlikely to have been greater than 50. Since one particle of each type has been observed to decay, we can therefore put $p \approx 0.02$. Setting $D \approx 30 \mathrm{~cm}$, , and $\beta=0 \cdot 7$, we find from equation (6) that $\tau_{0}=50 \times 10^{-8}$ sec.

We shall now discuss possible alternative explana. tions of the two forks.

Photograph I. We must examine the alternative possibility of Photograph 1 representing the spontaneous disintegration of a charged particle, coming up from below the chamber, into a charged and an uncharged particle. If we apply the argument which led to equation (4) to this process, it is readily seen that the incident particle would have a minimum mass of $1,280 \mathrm{~m}$. Thus the photograph cannot be explained by the decay of a back-scattered ordinary meson. Bearing in mind the general direction of the other particles in the shower, it is thought that assumption of the disintegration of a neutral particle moving downwards into a pair of particles of about equal mass is more probable. Further, it can be stated with some confidence that the observed ionizing particles are unlikely to be protons because the ionization of a proton of momentum $3.5 \times 10^{8}$ eV./c. would be more than four times the observed ionization.

Photograph 2. In this case we must examine the possibility of the photograph representing the spontaneous decay of a neutral particle coming from the right-hand side of the chamber into two charged particles. The result of applying equation (4) to this process is to show that the minimum mass of the neutral particle would be about $3,000 \mathrm{~m}$. In view of the fact that the direction of the neutral particle would have to be very different from the direction of the main part of the shower, it is thought that the original assumption of the decay of a charged particle into a charged penetrating particle and an assumed neutral particle is the more probable.

We conclude from all the evidence that Photograph 1 represents the decay of a neutral particle, the mass of which is unlikely to be less than $770 \mathrm{~m}$ or greater than $1,600 \mathrm{~m}$, into the two observed charged particles. Similarly, Photograph 2 represents the disintegration of a charged particle of mass greater than $980 \mathrm{~m}$ and less than that of a proton into an observed penetrating particle and a neutral particle. It may be noted that no neutral particle of mass $1,000 \mathrm{~m}$ has yet been observed; a charged particle of mass $990 \mathrm{~m} \pm 12$ per cent has, however, been observed by Leprince-Ringuet and L'héritier ${ }^{2}$.

Peculiar cloud-chamber photographs taken by Jánossy, Rochester and Broadbent ${ }^{3}$ and by Daudin ${ }^{4}$ may be other examples of Photograph 2.
It is a pleasure to record our thanks to Prof. P. M. S. Blackett for the keen interest he has taken in this investigation and for the benefit of numerous stimulating discussions. We also wish to acknowledge the help given us by Prof. L. Rosenfeld, Mr. J. Hamilton and Mr. H. Y. Tzu of the Department of Theoretical Physics, University of Manchester. We are indebted to Mr. S. K. Runcorn for his assistance in running the cloud chamber in the early stages of the work.

${ }^{1}$ Lattes, C. M. G., Occhialini, G. P. S., and Powell, C. F., Nature, $160,453,486$ '(1947).

Leprince-Ringuet, I., and I'héritier, M., J. Phys. Radium. (Sér. 8), 7, 66, 69 (1946). 'Bethe, H. A., Phys. Rev., 70, 821 (1946).

Jánossy, I., Rochester, G. D., and Broadbent, D., Nature, 155,1 42 (1945). (Fig. 2. Track at lower left-hand side of the photograph.) - Daudin, J., Annales de Physique, 11e Série, 19 (Avril-Juin), 1944 (Planche IV, Cliché 16).

\section{THE GRASSHOPPER PROBLEM IN NORTH AMERICA}

\author{
BY DR. B. P. UVARIOV, C.M.G. \\ Anti-Locust Research Centre, British Museum \\ (Natural History)
}

$\mathrm{O}^{2}$ FFICIAL figures compiled by the Division of Grasshopper Control of the United States Bureau of Entomology show that in the ten-year period 1936-46, crops to the value of $424,563,614$ dollars were destroyed by grasshoppers, and $26,088,211$ dollars was spent on control measures. No similar statistics are available for Canada, where the general situation with regard to grasshoppers is similar. The annual figures for the same period show considerable fluctuation, apparently dependent on natural variations in grasshopper populations; but they do not suggest any general downward trend which might be interpreted as a cumulative result of persistent artificial control measures. It must be stressed that these measures are unquestionably very successful so far as the protection of standing crops of the year is concerned, and the organisation of control, based on close co-operation of Federal and State agencies and the farmers, leaves little to be desired. Both the organisation and the technique of artificial control are being continually perfected, and it is estimated that, on the average, each dollar spent on grasshopper control serves to save crops to the value of 35 dollars. This is a remarkable achievement, and a large share of credit for it belongs to the Division of Grasshopper Control, admirably organised and run by Dr. Claude Wakeland and his staff. Nevertheless, it is clear that the protection of crops by direct control methods ceinnot be relaxed, and efforts on an ever-increasing scale will have to continue indefinitely. The policy of direct control is a palliative which cannot lead towards a lasting solution of the grasshopper problem in the North American continent.

This state of affairs has been realized by entomologists of the United States and Canada for some time, and their views were forcibly expressed in the following resolution adopted at a session of the Committee on Grasshopper Research at Lincoln, Nebraska, in 1946: "Millions of dollars have been appropriated and spent during the past twenty years by state, provincial, federal and dominion agencies for materials and labour for the applied control of grasshoppers. During the same period, the amount of money spent on research for a solution of the grasshopper problem has been woefully inadequate. 
We are convinced that each million dollars spent on grasshopper research now will save hundreds of millions to the people of the United States and Canada in future omergencies." The Lincoln Conference elaborated a programme of research and recommended that such research should be coordinated for the whole continent by a permanent Committee on Grasshopper Research of the American Association of Economic Entomologists, through a 'research co-ordinator' whose duty it would be to stimulate research, to assist it and to ensure the co-operation between different research agencies. The important practical question of establishing and financing the 'co-ordinatorship' remained, however, unsolved.

The next session of the Committee on Grasshopper Research was held at St. Paul, Minnesota, in March 1947, and I had the privilege of taking part in the discussions. Afterwards, I was able to visit several of the most important centres of grasshopper research in the United States and Canada and to study their work on the spot. The impressions gained during this short visit may have been incorrect, and are certainly incomplete; but they are of considerable general interest as an illustration of a research policy diverted from its ultimate objective by temporary influences.

All programmes of grasshopper research both in the United States and in Canada are dominated by the need to produce immediate practical results, on which year-to-year financing of research depends. Therefore, two items of research are in the foreground. One is the testing of new insecticides, which are continually appearing on the market. Little fundamental research on insecticide action is in evidence, but purely empirical evaluation of effectiveness and cost take a vast amount of time and energy of research workers. It was somewhat disconcerting to see almost the whole entomological staff of the Federal Grasshopper Research Section occupied for weeks in carrying out field-tests of new insecticides, without any technical assistants or labour. The explanation was the very high cost of labour; but the use of qualified research workers for actual field operations appeared a very questionable measure of economy.

The second problem absorbing research workers is grasshopper survey. Systematic surveys of grasshopper populations were introduced more than ten years ago, and since then three annual surveys (nymphal, adult and eggs) are carried out regularly over all States subject to infestation. Survey methods, sampling technique and the analysis of the data are very elaborate and are standardized throughout, so that, theoretically, one would expect the surveys to produce a vast accumulation of data of great value for an analysis of population trends and the factors regulating populations. Unfortunately, the surveys are primarily intended to provide a statistical basis for the assessment of the expected infestation and for the calculation of quantities of control materials. The value of the survey data for population studies is undoubtedly very great; but the execution of surveys and purely statistical computation of their results appear to occupy practically the whole time of the survey personnel. It was instructive to see how an admirably conceived and perfectly organised machinery for collecting scientific data of great value has enslaved its creators and has made it almost impossible for them to do anything beyond routine work. The amount of the accumulated data is now so great that it would take a team of research workers several years to analyse this material. There is no doubt that such an analysis would provide information on the sources of grasshopper outbreaks and on the factors controlling them ; this information would form a basis for formulating a long-range policy directed towards a lasting prevention of grasshopper outbreaks, instead of annual campaigns achieving only temporary relief; but it is apparently very difficult to make the administration realize the need for any expenditure that does not promise immediate return.

The soundness of the idea of grasshopper prevention was freely admitted by American and Canadian colleagues, but they were clearly of the opinion that, under present conditions, it would be futile to contemplate such a policy, which requires planning and execution on a continental scale. This close dependence of an entomological problem on the social structure of the country is most strikingly illustrated by the example of the grasshopper situation in the Phonix valley of Arizona. It is a wide irrigated plain where cotton cultivation prevailed in the past; but during the Second World War a rise in the price of alfalfa seed caused a great extension of the latter crop. Irrigated alfalfa fields in a semi-desert climate of Arizona provided ideal conditions for Melanoplus mexicanus and enabled it to produce up to three generations in a year instead of the normal one. A most serious infestation by this species has developed, and repeated applications of control methods are required to save the crop. Even a cursory examination of the area has suggested that some less wellcultivated fields, with patches of grass, may be the sources of infestation, and a general application of certain cultivation methods may have a far-reaching effect. The possibility of this approach was admitted, but it was pointed out that it will never be possible to induce all growers of alfalfa to adopt improved methods, particularly because in that area the cultivation of alfalfa on such a large scale is due mainly to the high and possibly only temporary profits. Should the price fall, alfalfa will be abandoned in favour of another crop. Under such conditions, any long-range policy is useless to contemplate, and palliatives must continue to be employed. Sooner or later, they may become too costly in relation to the crop value, and the problem of long-range prevention will inevitably arise. It might be a sound policy at least to commence research in that direction before the crisis becomes acute; but it does not appear possible to expect that the necessary funds would be obtainable for a long-range research which does not promise an immediate profit.

Apart from the enforced wrong emphasis in the research programmes, they suffer from a lack of co-ordination. A striking fact is that although certain grasshoppers, notably Melanoplus differentialis, are very extensively used in universities as laboratory animals, such research as is carried out in universities is entirely disconnected from field-work executed by the federal grasshopper research agencies, by experimental stations and by the agencies engaged in grasshopper surveys. At the meetings of the Committee on Grasshopper Research, university research workers were conspicuous by their absence, with very few exceptions. As a result, field investigators are often very backward in their approach to the problem, while university workers do not know of the existence of a large number of problems of grasshopper biology which arise in the field but can only be solved in the Iaboratory. 
The need for co-ordinating all grasshopper research has been repeatedly stressed by the Committee on Grasshopper Research, but the impression was that this is an aspiration rather than a demand for a practical measure. It would be natural to suggest that co-ordination of grasshopper research might be organised, or at least financed, jointly by the Governments of the two North American countries, but somehow this appeared to be impracticable.

In spite of all handicaps, American entomologists are making great strides in the study of the grasshopper problem. Unfortunately, their achievements are insufficiently known, since surprisingly little has been published on the subject, mainly because the routine work leaves no time for analysing and sum. marizing the results. It was even more surprising to hear that many important papers have been ready and waiting for publication for some years. Lack of funds as an explanation did not sound very convincing for a European visiting the United States. The Committee on Grasshopper Research has passed a very strong recommendation that the analysis of accumulated data and the publication of results should be speeded up; but it remains to be seen what the official reaction will be.

It is impossible here to discuss details which would be of interest only to specialists, who have a great deal to learn from the experience of American colleagues, particularly with regard to the technique and the organisation of grasshopper control. A much wider interest is attached to the general aspects of the North American grasshopper problem and its treatment. There is no doubt whatever that the problem is a man-made one, and it reached its great economic importance as a result of land development which was rapid, extensive and unscientific. A rapid expansion of unplanned agriculture in the North American continent has created exceptionally favourable conditions for various insect pests and for grasshoppers in particular. An analogous situation is rapidly developing in Australia, and it is only a matter of time before Africa will be faced with similar results of extensive agricultural development. There is in Africa a vast and varied grasshopper fauna, many members of which will undoubtedly develop into dangerous pests as soon as suitable soil conditions and abundant food are provided for them by the clearing of forests and by mechanized agriculture. At present, African development is threatened by locust plagues, which are a serious factor, but a periodical one; grasshopper plagues, although less spectacular than locust invasions, will be much more serious in their aggregate effects because they tend to be perennial, as the example of North America shows. Anti-locust policy in Africa is developing on the lines of prevention, and it became possible to formulate such policy only after some twenty years of international research. It will take a long time to study the possible effects of mechanized agriculture on native grasshoppers, and it is therefore not too early to consider commencing such studies. The alternative is to do nothing until the danger becomes imminent, by which time it may be too late for any measures of prevention, and perennial artificial control will be required. Again, the American example shows that such control is very expensive and only highly remunerative crops can stand the cost. Agricultural development of Africa is now being planned on a vast scale, and it may be wise not to forget possible handigaps.

\section{ATMOSPHERIC TURBULENCE}

ANY workers in atmospheric turbulence prob1 ably believe the subject to be more readily capable of formal and exact development than some other branches of dynamical meteorology, a belief deriving from a certain measure of success already attained. But that this success is rather slight is evident when one considers that there is still only slight understanding of turbulence in isothermal flow such as occurs in wind tunnels, pipes, etc., while the atmospheric problems are complicated by the existence of buoyancy forces, positive or negative, by the earth's rotation, and, over the oceans, by the form of the surface being dependent on the air motion itself. Again, there is a very considerable difference in scale between laboratory and atmospheric flow; but this difference may well be ultimately profitable to an improved understanding of turbulence on all scales-solar, terrestrial (atmospheric and oceanic), and laboratory.

G. I. Taylor effectively established the subject of atmospheric turbulence in his classical paper of 1915 . From observations of temperature on the Eiffel Tower and by kite over the Newfoundland Grand Banks, and from Dobson's observations of wind speed and direction in the first kilometre or so over Salisbury Plain, Taylor deduced that the turbulence of the lower atmosphere resulted in an effective coefficient of diffusion of heat or of momentum some $10^{4}-10^{6}$ times greater than the value for molecular diffusion, the ratio increasing with the wind speed and the lapse-rate of temperature. The equations of heat or momentum transport by which these results were obtained were solved by assuming the turbulent diffusivity constant through the layer concerned, whereas on any simplified picture of eddy motion a variation with height appeared probable; and this variation was involved in the next major advance in the subject early in the last decade. The advance was derived from Prandtl's application of mixing-length ideas growing out of earlier work by Taylor and Schmidt, the mixing-length being an analogue in eddy motion of the mean free path of molecular theory and connoting the mean length of path over which turbulent elements move between birth and extinction, that is, between acquiring and losing a velocity different from that of the mean motion at the levels in question. Prandtl assumed that near a boundary the mixing-length increased linearly with distance from the boundary, and by assuming further that the turbulent elements conserved their momentum during motion (that is, pressure field of no immediate consequence) he deduced that the mean velocity should increase with the logarithm of the distance from the boundary in the region of negligible variation of turbulent shearing stress. This result was in accord with observations in the laboratory for a very wide range of Reynolds number, and in the first $10 \mathrm{~m}$. or so of the atmosphere when in near-neutral static equilibrium. The mixinglength distance relation, more or less confirmed by this agreement of theory with observation, implied that turbulent diffusivity increased linearly with distance from the boundary and was given directly, for momentum transfer at least, from observations of the velocity profile.

Early in the 1920's, L. F. Richardson had examined the effect of static stability on the rate of growth or decay of turbulence. He showed that the rate of production of turbulent energy due to a velocity 